\title{
Facial Plastic Surgery Faculty Turnover: Survey of Academic Facial Plastic Surgeons and Department Chairs
}

\author{
David Michael Kowalczyk ${ }^{1}$ J J Randall Jordan ${ }^{1}$ \\ ${ }^{1}$ Department of Otolaryngology, The University of Mississippi \\ Medical Center, Jackson, MS, United States \\ Int Arch Otorhinolaryngol 2019;23:209-217.

\begin{abstract}
Address for correspondence David Michael Kowalczyk, MD, MBA, Department of Otolaryngology, The University of Mississippi Medical Center, 2500 N State St, Jackson, MS, 39216, United States
\end{abstract} \\ (e-mail: dkowalczyk@umc.edu).
}

\begin{abstract}
Keywords

- plastic surgery

- surveys and questionnaires

- otolaryngology

Introduction The turnover and inability to consistently retain academic facial plastic surgeons is an issue that many academic departments of otolaryngology face. In addition to the financial costs of staff turnover and gaps in patient care, insufficient exposure of residents to key surgical procedures is a significant problem for residency programs.

Objective To identify the most important reasons that lead faculty members to leave an academic facial plastic surgery (FPS) practice as well as features that may be associated with retention of FPS faculty.

Methods Members of the American Academy of Facial Plastic and Reconstructive Surgery (AAFPRS) and the Association of Academic Departments of Otolaryngology (AADO) were administered an anonymous, online survey. For both groups, we evaluated demographic factors, reasons for choosing academic careers, contributors to faculty turnover, as well as strategies for retention. The frequency of the responses was analyzed.

Results A total of $11.3 \%(135 / 1,200)$ of facial plastic surgery faculty responded to the faculty survey, with $59.1 \%$ (68/115) of current, academic surgeons participating, and a total of $16.7 \%(20 / 120)$ of department chairs responded to the chairs' survey. If a faculty member had left/was to leave, more control over practice was the most common reason between the two respondent groups. Of the five most important ways to increase faculty retention, more control over practice was the number one reason. Conclusion Chairs and facial plastic surgery faculty should strive to agree upon the amount of control over the academic practice to lead to higher retention, better patient care, and continued resident education.
\end{abstract}

\section{Introduction}

Academic medicine affords a unique opportunity for physicians to engage in an environment of continual learning, resident and medical student education, complex clinical and surgical care, and pioneering research. Those who have

(DD) David Michael Kowalczyk's ORCID is https://orcid.org/00000003-0553-9382.

received

May 28, 2018

accepted

August 5, 2018

published online

February 15, 2019 completed a medical degree, in addition to a graduate degree or fellowship, have the highest association with choosing a career in academic medicine. ${ }^{1}$ Although the majority will have fruitful careers, $14 \%$ of academic physicians have considered leaving their current institution within the past year, and another $21 \%$ have considered leaving academic medicine altogether. ${ }^{2}$ Administrative tasks and paperwork, such as navigating electronic health records, Meaningful Use (MU), and maintenance of certification, were cited as major

Copyright $\odot 2019$ by Thieme Publicações License terms Ltda, Rio de Janeiro, Brazil

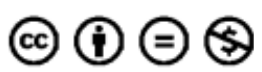


reasons for academic physician dissatisfaction, accounting for up to $24 \%$ of the physician's working hours. ${ }^{3}$ The cost associated with losing an academic faculty member is estimated to be between $\$ 155,000$ and $\$ 559,000$, with repercussions not only in having a void in the faculty roster, but moreover, gaps in patient care and resident education. ${ }^{2}$ In today's cost-conscious healthcare system, academic medical centers are trying to contain costs more effectively and thus, greater pressure is being exerted on academic faculty members to accomplish similar ends with less resources.

The impact of retention and turnover among academic surgeons has become an important issue studied more recently. Pay and benefits are evident factors involved in the decision to stay at a particular academic medical center. But, promotion equality, collegiality and collaboration, and the nature of their work were considered the most paramount reasons for academic surgical specialists to stay at their current position. ${ }^{4}$ In the field of academic plastic surgery, the issues of turnover and lack of faculty retention have been explored. An institution's misconception that plastic surgery is frivolous, ambiguous, and nonessential has presented significant challenges for these departments. ${ }^{5}$ The field of facial plastic surgery (FPS), to our knowledge, has limited literature regarding faculty members turnover and retention.

In our study, we create two surveys for two different groups-academic facial plastic surgeons and Chairs of academic departments of Otolaryngology in North America. Each survey will seek to identify key factors regarding turnover and retention of these types of faculty members. By determining any commonalities between the two groups, we hope to (1) generate awareness for issues that can be brought not only to an institution's attention, but also to physician organizations at a national level, (2) decrease gaps in patient care when faculty depart, and (3) encourage consistent, resident education and exposure to the field of FPS.

\section{Methods}

Two distinct surveys were created by the authors, each of which was intended for a specific group-academic facial plastic surgeons or academic chairs of otolaryngology departments. The surveys were intended to be completed in less than 5 minutes and were distributed in a user-friendly interface using the SurveyMonkey software (SurveyMonkey, San Mateo, CA). The total number of questions were 12 and 9, respectively, and there was a section at the end for comments. No institution review board approval was necessary.

To keep anonymity of those completing the surveys, the assistance of the American Academy of Facial Plastic Surgery (AAFPRS) and the Association of Academic Departments of Otolaryngology (AADO) were enlisted. The Survey of Academic Facial Plastic Surgeons was sent to the AAFPRS for approval, while the survey of department chairs regarding faculty facial plastic surgeons was sent to AADO. Once each was approved, the SurveyMonkey link was distributed to each respective member securely from the specific organization's email. The survey period for the survey of academic facial plastic surgeons was from 9/11/17 through 10/31/17 while the survey of department chairs regarding faculty facial plastic surgeons was $10 / 10 / 17$ through $12 / 6 / 17$. The variation in survey periods was attributed to differences in the approval process from the previously mentioned organizations. The results of the surveys were analyzed.

\section{Survey of Academic Facial Plastic Surgeons}

This survey was sent to 1,200 members of the AAFPRS and consisted of 12 questions ( Table $\mathbf{1}$ ). There are 115 members (115/1,200 or $9.6 \%$ ) currently involved in academics, according to the AAFPRS. We evaluated the respondent's current job status, number of institutions worked, gender, years in practice, current income, reasons for choosing an academic career and timing of the decision, highest position held, practice structure, current benefits, reasons for leaving, and strategies for retention.

\section{Survey of Department Chairs Regarding Faculty Facial Plastic Surgeons}

This survey was sent to 120 members of the AADO and consisted of 9 questions ( $\mathbf{-}$ Table $\mathbf{2}$ ). We evaluated the number of facial plastic surgery faculty members, presumed reasons for each faculty's choosing of academics, the duration of tenure and highest position held, benefits provided, reasons for leaving academics, and important strategies for faculty retention.

\section{Results}

\section{Survey of Academic Facial Plastic Surgeons}

A total of $11.3 \%(135 / 1,200)$ of facial plastic surgeons responded to the survey. Approximately $74.1 \%$ (100/135) were involved in academics at some point in their career, with 50.4\% (68/135) currently involved. There were $68.0 \%$ $(68 / 100)$ of respondents that were part of only 1 institution and $86.5 \%$ (90/104) were male. About $34.7 \%$ (35/104) of the respondents practiced for longer than 21 years and $57.6 \%$ (57/99) made more than $\$ 400,000$ annually. The 3 most common reasons for choosing an academic position were a desire to teach residents and medical students (92.1\% or 93/ $101)$, complexity of clinical cases $(70.3 \%$ or $71 / 101)$, and collegial environment (64.4\% or $65 / 101)$. Fifty-two percent (52/100) of the respondents made the decision to pursue an academic position during residency and 49.5\% (49/99) held assistant professor titles. A practice structure with more than $75 \%$ of the surgeries being reconstructive was identified in $47.0 \%(47 / 100)$ of the cases. The following 3 benefits were offered most commonly besides retirement, flexible spending, disability, and life/health plans: travel, meeting, and continuing medical education (CME) funds ( $82.8 \%$ or $77 / 93$ ); paid relocation expenses (47.3\% or 44/93); protected research time $(24.7 \%$ or $23 / 93$ ) (-Fig. 1 ). If a respondent had left or would leave an academic position, the 3 most common reasons were: lack of control over practice $(68.0 \%$ or $66 / 97$ ); pay/benefits (59.8\% or 58/97); work/life balance (34.0\% or 33/97) (-Fig. 2). The top five most important strategies for retention of FPS faculty members were: (1) more control over practice; (2) ability to market practice; (3) 
Table 1 Survey of academic facial plastic surgeons

\begin{tabular}{|c|c|}
\hline Q1. & $\begin{array}{l}\text { Are/have you been an academic facial plastic surgeon? } \\
\text {-_ Yes, currently } \\
\text {-_ Yes, formerly } \\
\text { _- No (If 'No' checked, please stop the survey) }\end{array}$ \\
\hline Q2. & $\begin{array}{l}\text { If so, how many academic positions have you held? } \\
-1 \\
--2 \\
- \\
-\end{array}$ \\
\hline Q3. & $\begin{array}{l}\text { What is your gender? } \\
\text {-_ Male } \\
\text { _- Female }\end{array}$ \\
\hline Q4. & 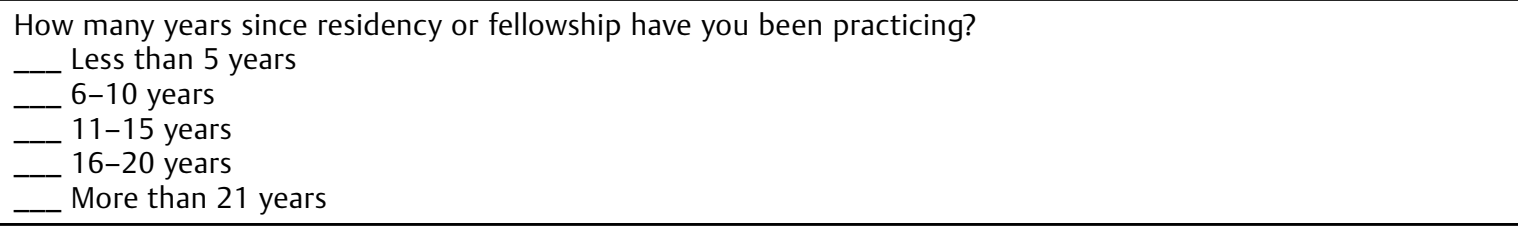 \\
\hline Q5. & 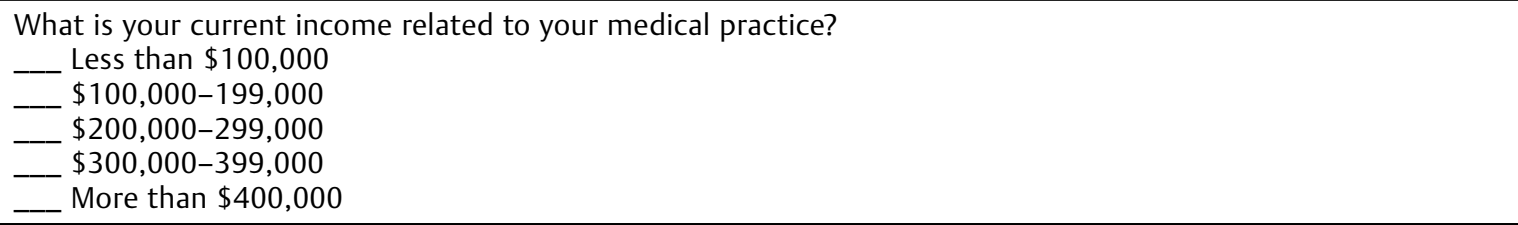 \\
\hline Q6. & 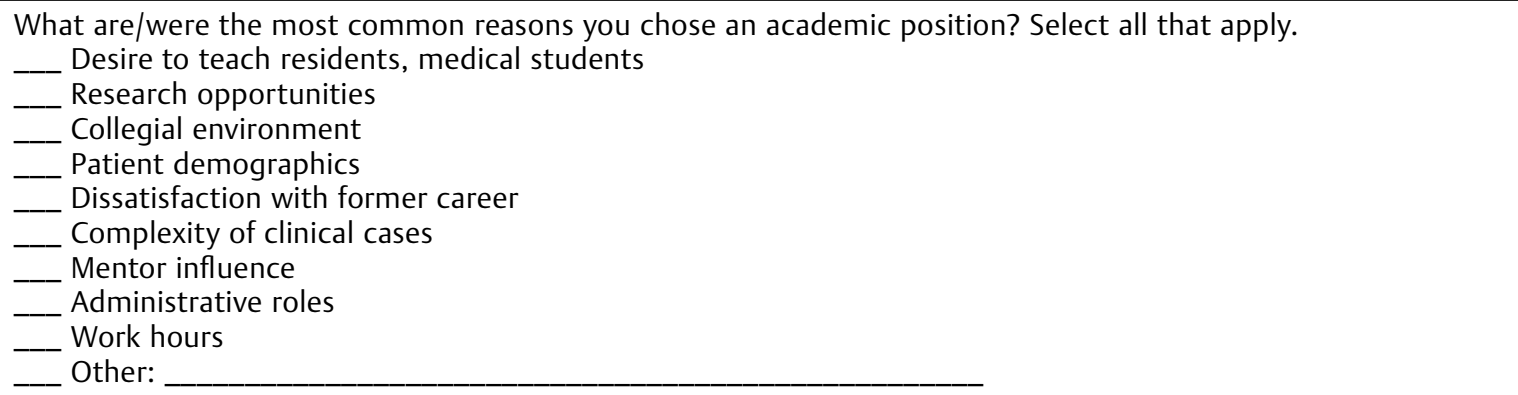 \\
\hline Q7. & $\begin{array}{l}\text { At what point in your training or career did you know you wanted to pursue an academic position? } \\
\text { - Prior to medical school } \\
\text { - Medical school } \\
\text { - Residency } \\
\text { - } \text { Fellowship } \\
\text { __- Private practice }\end{array}$ \\
\hline Q8. & $\begin{array}{l}\text { What is/was your highest position held while in academia? } \\
\text { Assistant professor } \\
\text { ___ Associate professor } \\
\text { ___ Professor }\end{array}$ \\
\hline Q9. & $\begin{array}{l}\text { How is/was your practice structured? } \\
\text { Greater than } 75 \% \text { cosmetic } \\
\text { ___ Greater than } 75 \% \text { reconstructive } \\
\text { ___ Roughly } 50: 50\end{array}$ \\
\hline Q10. & $\begin{array}{l}\text { Which of the following benefits other than retirement, flexible spending, disability, and life/health plans are/were } \\
\text { offered to you as a faculty member? Select all that apply. } \\
\text { Paid relocation expenses } \\
\text { Student loan payoff assistance } \\
\text { Protected research time } \\
\text { Funds for research projects } \\
\text { Advanced practice provider (nurse practitioner, physician assistant) support } \\
\text {-_ Signing bonus } \\
\text { Travel, meeting, and continuing medical education (CME) funds } \\
\text { Other: }\end{array}$ \\
\hline Q11. & $\begin{array}{l}\text { What are/were the most common reasons you left/would leave an academic position? Select all that apply. } \\
\text { Retirement } \\
\text { Operating room (OR) availability }\end{array}$ \\
\hline
\end{tabular}


Table 1 (Continued)

\begin{tabular}{|c|c|}
\hline & $\begin{array}{l}\text { Work/life balance } \\
\text { C__ Call responsibilities } \\
\text { Moved to another academic program } \\
\text { ___ Joined a private practice } \\
\text { Lack of control over practice } \\
\text { D__ } \text { Discrimination, gender barriers } \\
\text { Time commitment } \\
\text { Pa_ Pay/benefits } \\
\text { Other: }\end{array}$ \\
\hline Q12. & 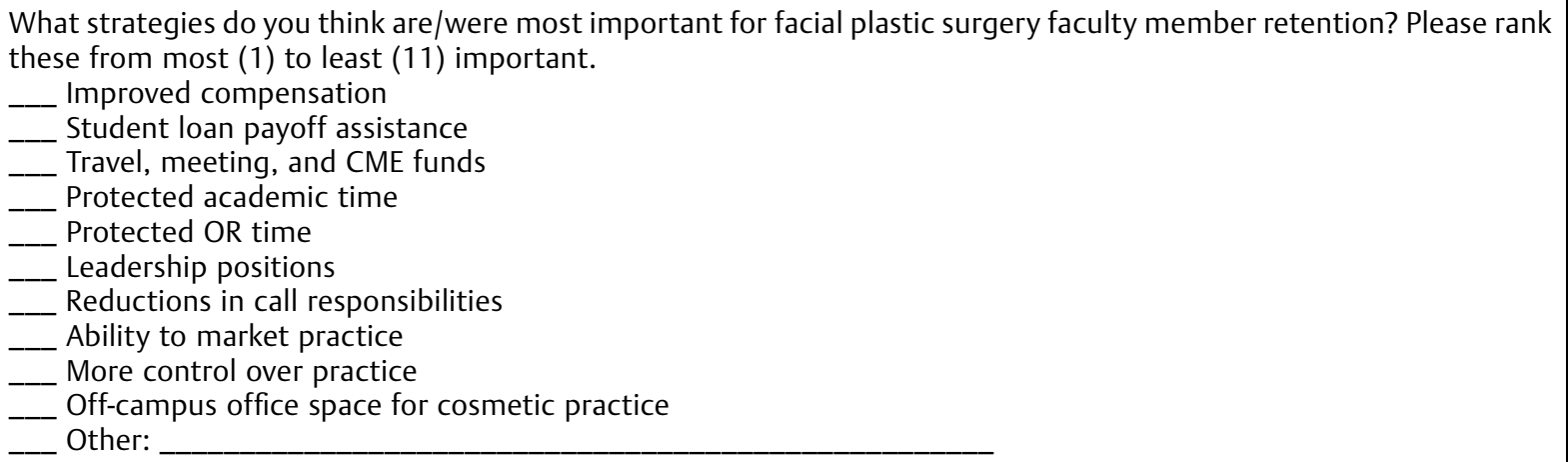 \\
\hline
\end{tabular}

Table 2 Survey of department chairs regarding faculty facial plastic surgeons

\begin{tabular}{|c|c|}
\hline Q1. & $\begin{array}{l}\text { Within your department, are/have there ever been any facial plastic surgeons? } \\
\text { Yes } \\
\text { ___ No (if 'No' checked, please stop the survey) }\end{array}$ \\
\hline Q2. & 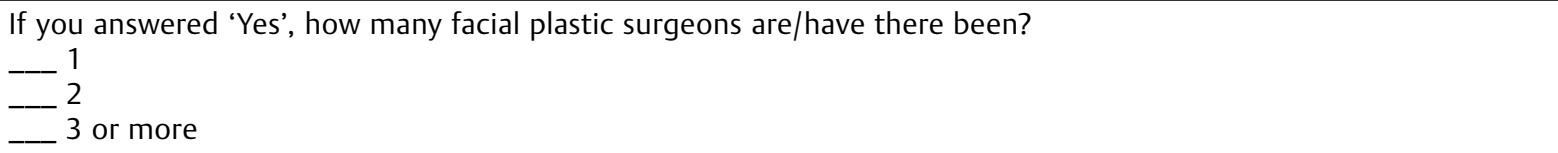 \\
\hline Q3. & $\begin{array}{l}\text { What do you think are/were the most common reasons these individuals chose an academic position? Select all that } \\
\text { apply. } \\
\text { Desire to teach residents, medical students } \\
\text { Research opportunities } \\
\text { C__ Collegial environment } \\
\text { Patient demographics } \\
\text { Dissatisfaction with former career } \\
\text { C__ Complexity of clinical cases } \\
\text { Mentor influence } \\
\text { _-_ Administrative roles } \\
\text { Work hours } \\
\text { Other: }\end{array}$ \\
\hline Q4. & $\begin{array}{l}\text { How long have they been faculty members? Select all that apply. } \\
\text { Less than } 1 \text { year } \\
\text { 2-5 years } \\
\text { 6-10 years } \\
\text { More than } 10 \text { years }\end{array}$ \\
\hline Q5. & $\begin{array}{l}\text { What are/were their highest positions held while in academia? Select all that apply. } \\
\text { Assistant professor } \\
\text { Associate professor } \\
\text { P Professor }\end{array}$ \\
\hline Q6. & $\begin{array}{l}\text { How are/were their practices structured? Select all that apply. } \\
\text { Greater than } 75 \% \text { cosmetic } \\
\text { __ Greater than } 75 \% \text { reconstructive } \\
\text { Roughly } 50: 50\end{array}$ \\
\hline
\end{tabular}


Table 2 (Continued)

\begin{tabular}{|c|c|}
\hline Q7. & $\begin{array}{l}\text { Which of the following benefits other than retirement, flexible spending, disability, and life/health plans are/were } \\
\text { offered to these faculty members? Select all that apply. } \\
\text { Paid relocation expenses } \\
\text { __ Student loan payoff assistance } \\
\text { Protected research time } \\
\text { _-_ Funds for research projects } \\
\text { Advanced practice provider (nurse practitioner, physician assistant) support } \\
\text {-_ Signing bonus } \\
\text { T_- Travel, meeting, and continuing medical education (CME) funds } \\
\end{array}$ \\
\hline Q8. & 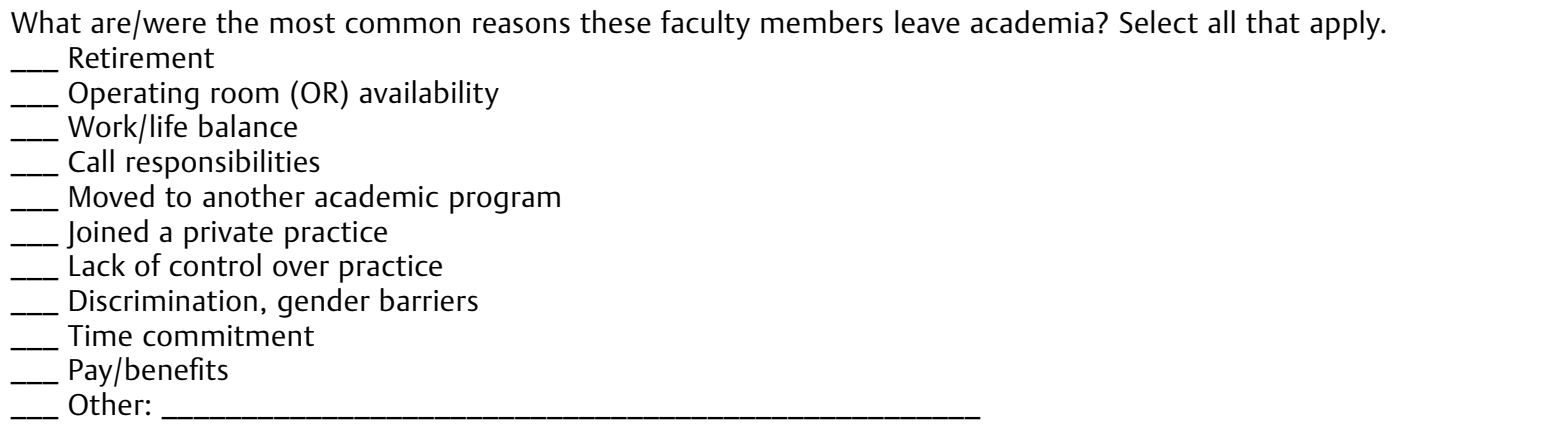 \\
\hline Q9. & 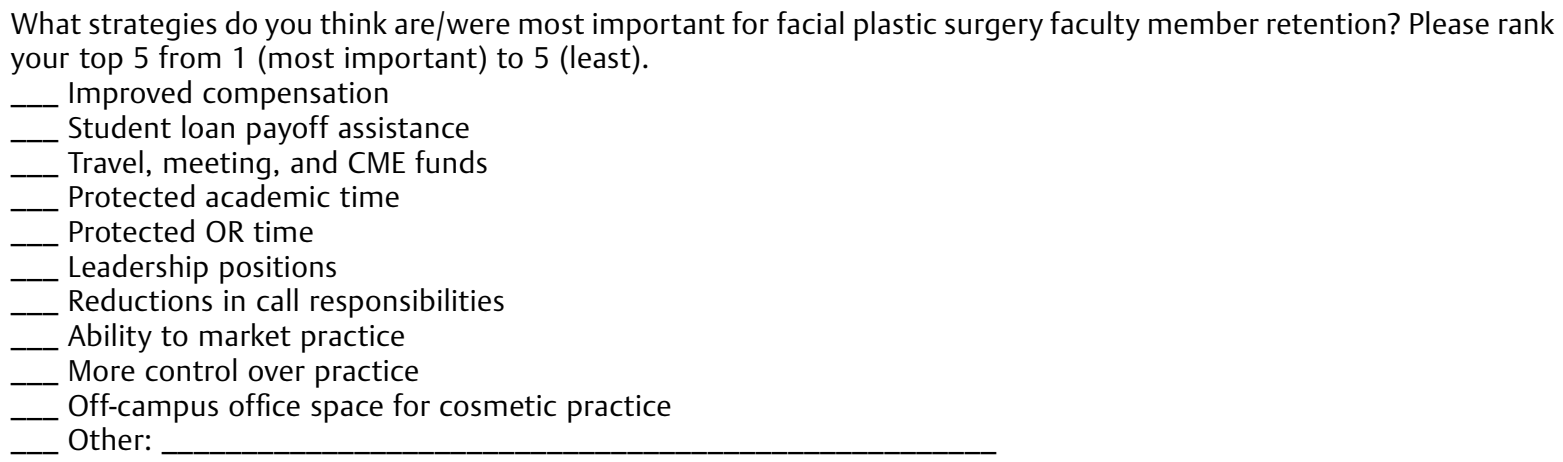 \\
\hline
\end{tabular}

improved compensation; (4) off-campus office space for cosmetic practice; (5) protected operating room (OR) time (-Fig. 3).

\section{Survey of Department Chairs Regarding Faculty Facial Plastic Surgeons}

A total of $16.7 \%$ (20/120) department Chairs responded to the survey. One-hundred percent (20/20) stated that he or she has or had a facial plastic surgeon on faculty. During the Chair's tenure, $55.0 \%(11 / 20)$ reported having 3 or more facial plastic surgeons on faculty. The top 3 speculated reasons these faculty chose an academic position were: desire to teach $(100.0 \%$ or $20 / 20)$ and the complexity of clinical cases $(80.0 \%$ or $16 / 20)$, with collegial environment and mentor influence tied at $55.0 \%(11 / 20)$. Most faculty members $(31.1 \%$ or 14/45) stayed longer than 10 years, with the highest average position being assistant professor $(51.0 \%$ or $26 / 51)$. Most faculty (42.6\% or $20 / 47$ ) had a practice that involved a 50:50 mixture of cosmetic and reconstructive procedures. The following 3 benefits were offered most commonly above retirement, flexible spending, disability, and life/health insurance plans: travel, meeting, and CME funds (100.0\% or
$20 / 20$ ); paid relocation expenses ( $75.0 \%$ or $15 / 20$ ); protected research time $(70.0 \%$ or $14 / 20)$. If a faculty member left or would leave an academic position, the 3 most common reasons were: joining a private practice $(45.0 \%$ or $9 / 20)$; lack of control over practice $(40.0 \%$ or $8 / 20)$; other $(35.0 \%$ or $7 / 20$ ) (-Fig. 4). The top five most important strategies for retention of FPS faculty members were: more control over practice (1); improved compensation (2); ability to market practice (3); off-campus office space for cosmetic practice (4); protected OR time (5) (-Fig. 5).

\section{Discussion}

Academic departments of otolaryngology continue to evolve with an increasingly important role filled by the specialty of FPS. These surgeons present an opportunity for patients, medical students, residents, and fellows to experience the robust nature of this specialty ranging from purely cosmetic to advanced, reconstructive procedures. Despite these benefits, there is significant pressure faced by academic departments from an institutional level to cut costs. A survey of academic medical centers by PricewaterhouseCoopers indicated that up 


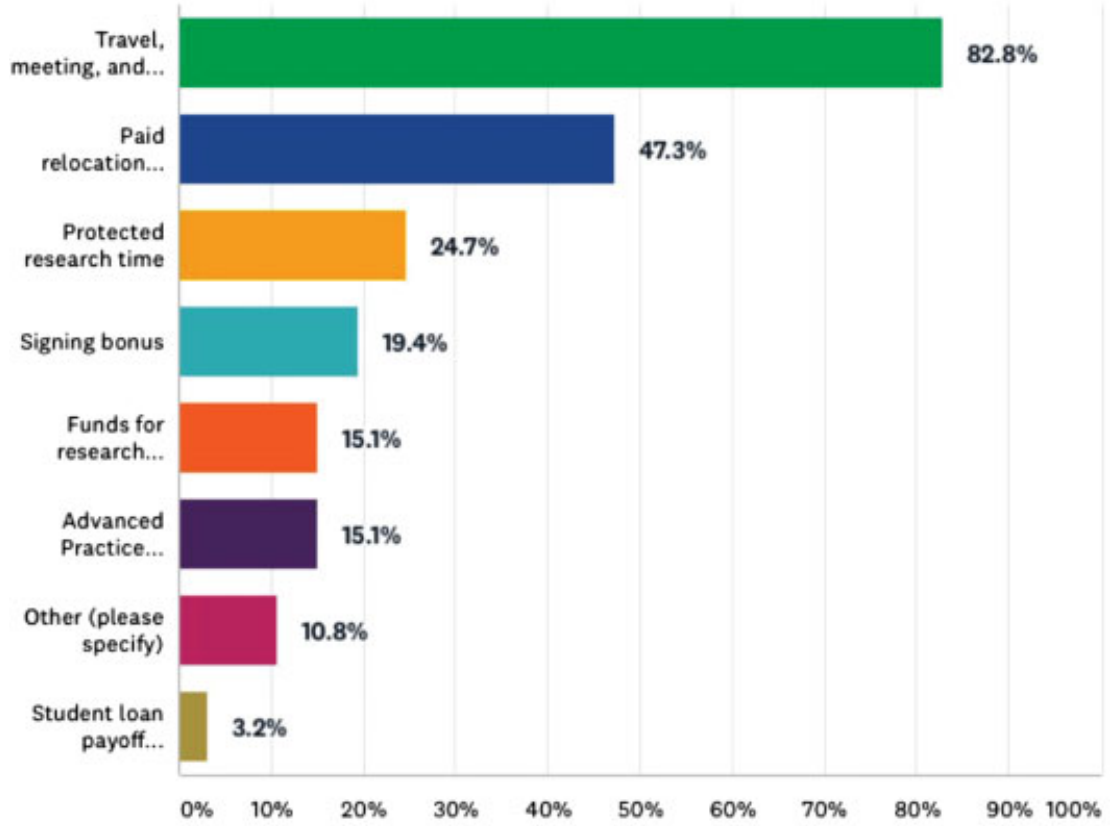

Fig. 1 Q10. Which of the following benefits other than retirement, flexible spending, disability, and life/health insurance plans are/were offered to you as a faculty member? Select all that apply.

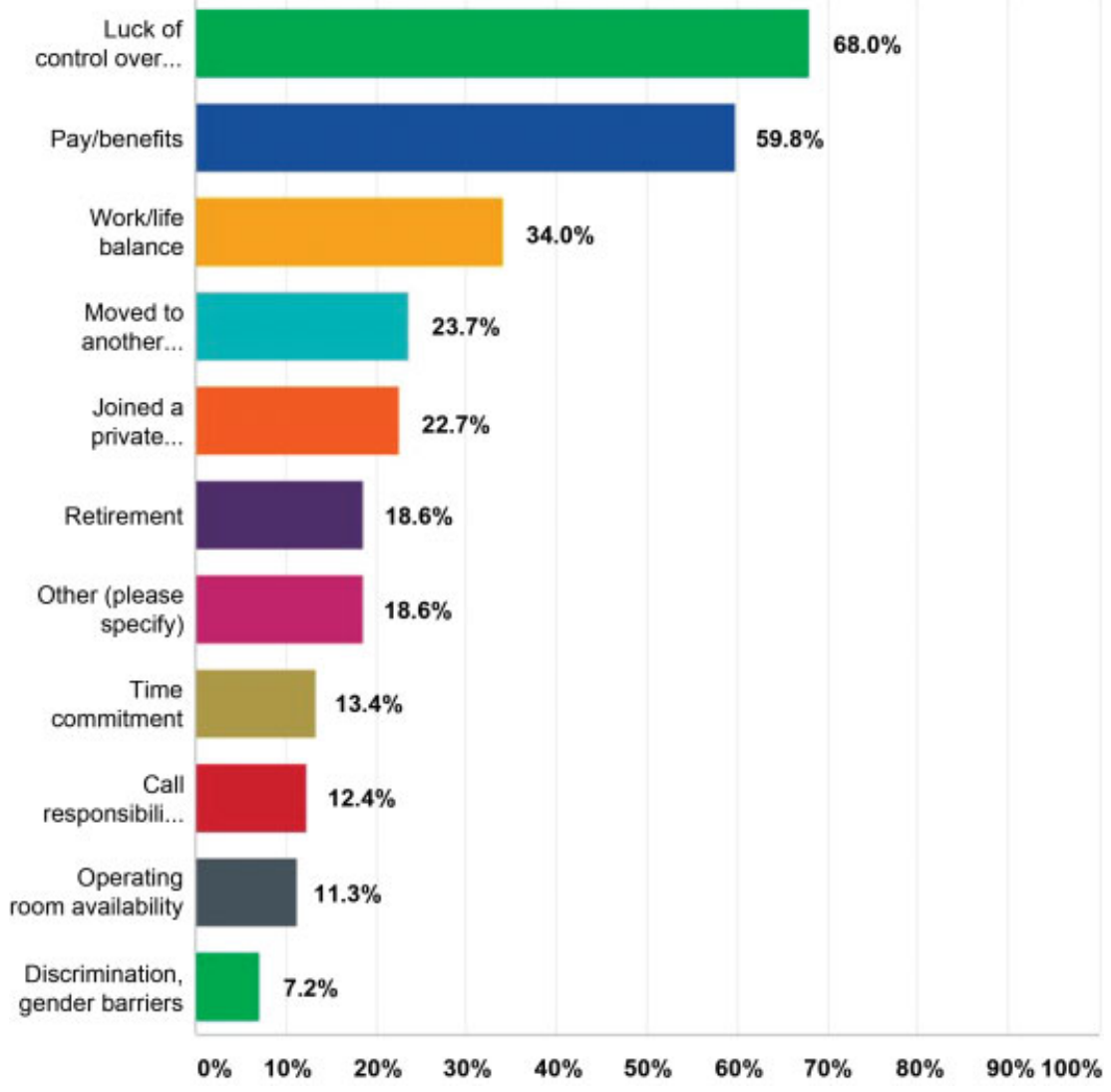

Fig. 2 Q11. What are/were the most common reasons you left/would leave an Academic position? Select all that apply.

to $10 \%$ of traditional revenue will be at risk in the next decade from external funding threats and increasing operating margins, averaging $5 \%$, which could lead to profit margins falling to zero. ${ }^{6}$ Unfortunately, such budget cuts affect these faculty members who perform procedures, particularly cosmetic, that are often seen as inconsistent with institutional missions, which highlight the need to serve the region's most vulnerable patient populations.

An article by Jumaily and Spiegel, published in 2015, detailed the unique needs for facial plastic surgeons in 


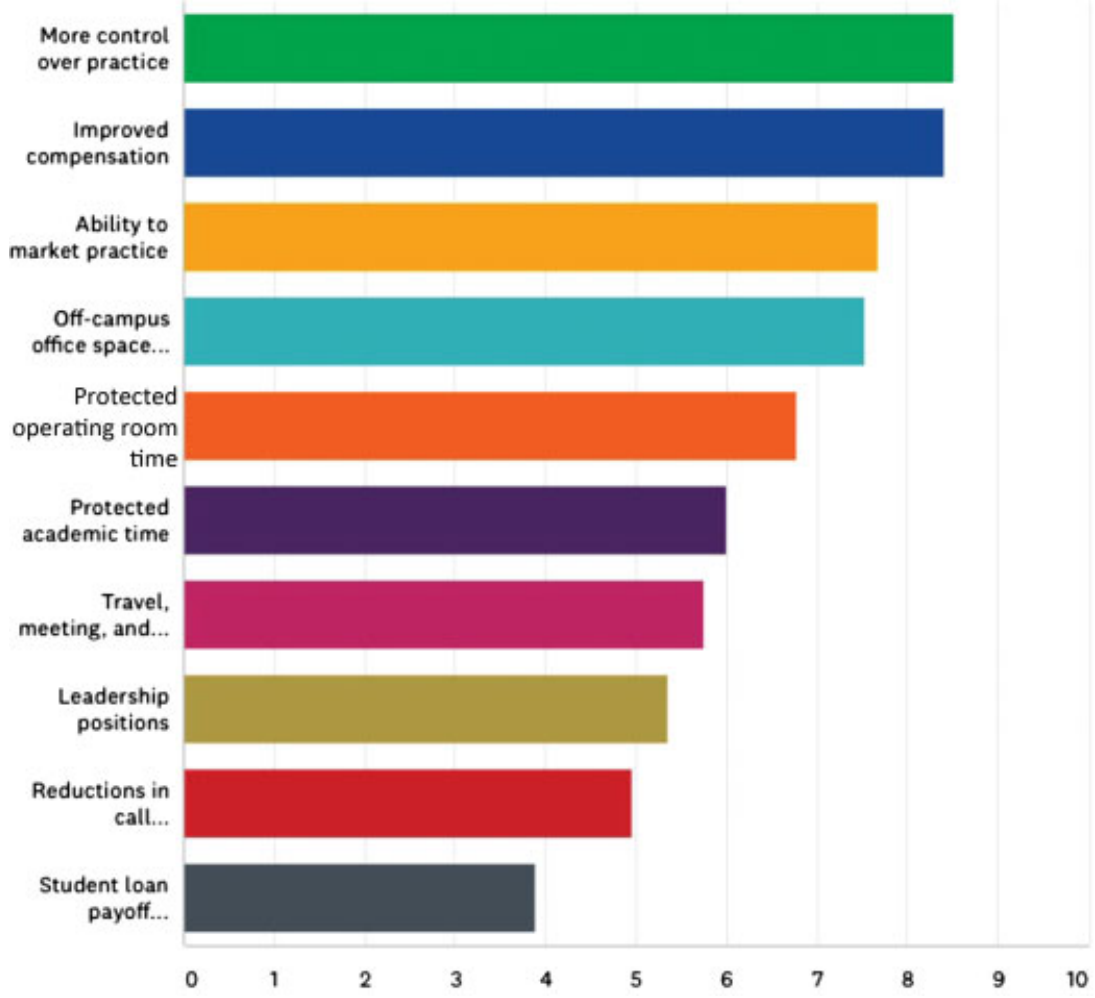

Fig. 3 Q12. What strategies do you think are/were most important for facial plastic surgery faculty member retention? Please rank these from most (1) to least (11) important.

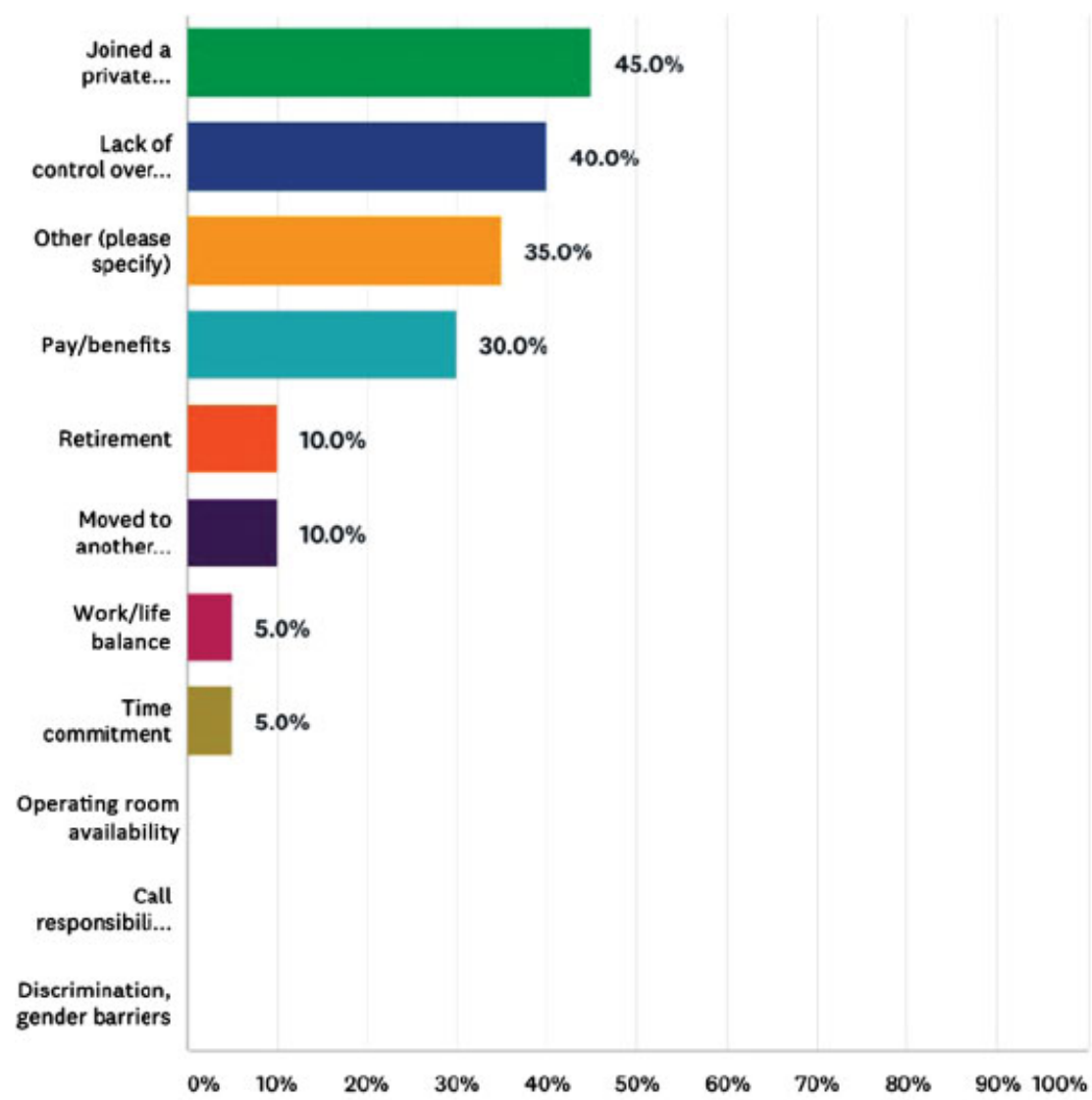

Fig. 4 Q8. What are/were the most common reasons these faculty members leave/left academia? Select all that apply. 


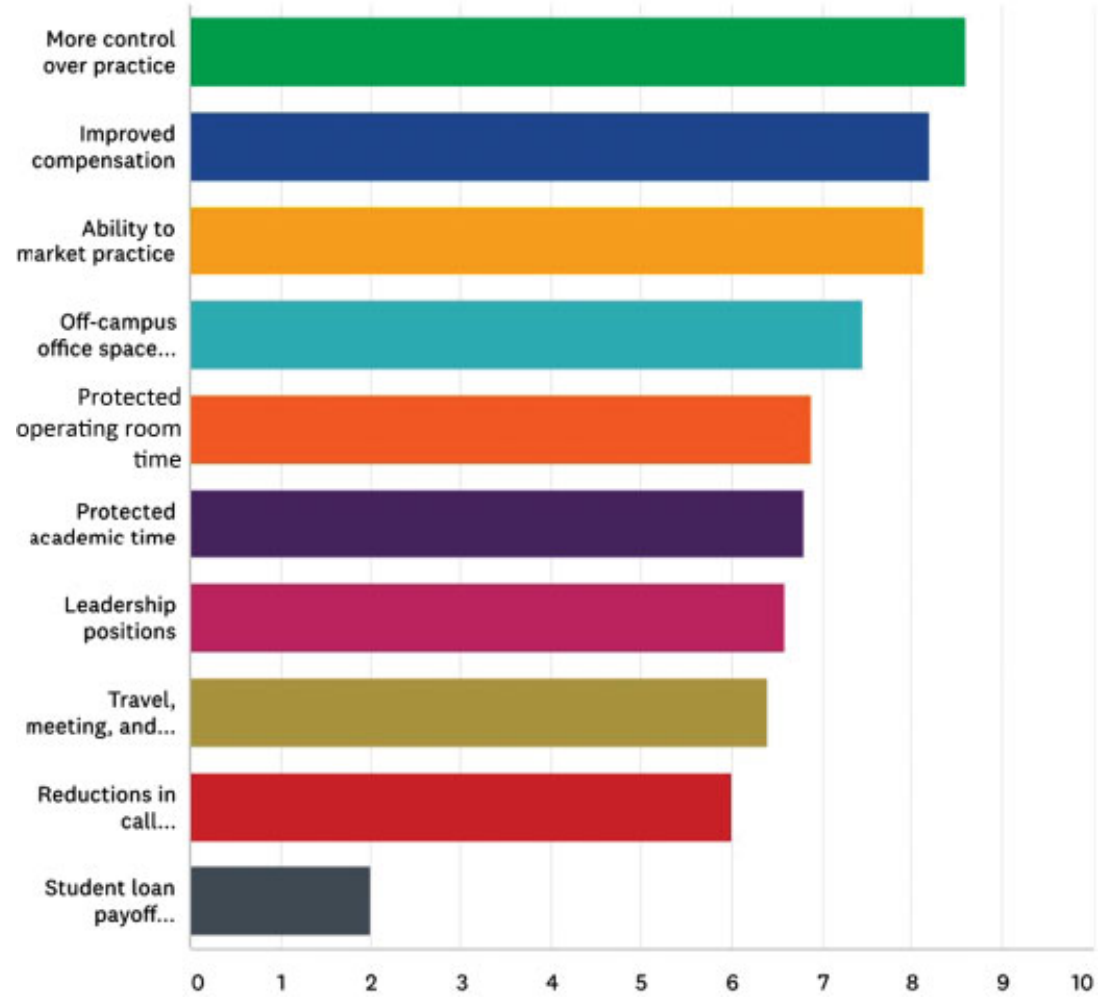

Fig. 5 Q9. What strategies do you think are/were most important for facial plastic surgery faculty member retention? Please rank your top 5 choices from 1 (most important) to 5 (least important).

academics. $^{7}$ A survey was created and sent to academic chairpersons in 2009 and 2013. The results of the survey demonstrated that there were increased costs associated with retaining these faculty members within academic institutions. Some of the challenges indicated were the need for specialized staff, costly equipment, upscale private space, and money needed to market these physicians against private practice physicians. On average, $34 \%$ of respondents were worried these faculty members would leave, and $65 \%$ found these surgeons profitable for the department. Over $80 \%$ of department chairpersons had built-in incentives for paying these faculty. Yet, only $6 \%$ of departments had a separate space-one that was independent of other otolaryngology space-for these faculty members.

Our results should be discussed regarding each survey as well as commonalities that exist. The survey of academic facial plastic surgeons had an $11.3 \%$ response rate, with nearly $75 \%$ being currently or formerly involved in academics. Despite the seemingly low overall response rate, we feel that we captured a representative sample of those currently known to be in academics with $68 / 115$ (59.1\%) responding to our survey. If a faculty member had left or would leave an academic position, the three most common reasons were lack of control over practice, pay/benefits, and work/life balance. The top five most important strategies for retention of FPS faculty were: (1) more control over the practice; (2) improved compensation; (3) ability to market practice; (4) off-campus office space for cosmetic practice; (5) protected OR time.

The survey of department chairs regarding faculty facial plastic surgeons had a $16.7 \%$ response rate. If a faculty member left or would leave an academic position, the three most common reasons were joining a private practice, lack of control over practice, and other. It is important to mention the response of other from this question. The comments were analyzed, and it appears that a majority selected this choice to indicate 'not applicable' and 'increased pay.' This confusion makes this response less credible and suggests that pay/benefits, the fourth most common reason, should actually be in the top three. The top five most important strategies for retention of these faculty members were: more control over practice (1); improved compensation (2); ability to market practice (3); off-campus office space for cosmetic practice (4); protected OR time (5).

The commonalities between the results of the two surveys are integral for assisting with future retention and decreasing turnover. There were multiple survey questions that exhibited strong commonalities. The additional benefits provided to faculty were similar. If a faculty member was to leave, more control over practice was a shared reason. The five most important ways to increase faculty retention were the same between the two groups, with more control over practice being the number one reason. It is interesting to note that one of the reasons for choosing academics-the collegial environment-was chosen by Chairs and facial plastic surgeons. The ability to work in an environment especially where opportunities exist for mentoring is vital for physician retention in academics. ${ }^{8}$ We believe this is one area where Chairs can continue to further foster the development and retention of their facial plastic surgery faculty members. 
A section for comments was provided for each survey. Many facial plastic surgeons emphasized the difficulties of dealing with "administration," the "time it takes to build an academic practice," and "frustrations with performing cosmetic procedures" when competing against private practice colleagues. A suggestion was made for "different compensation strategies" based on the surgeon's primary focus-reconstruction or cosmetics-to reduce the risk for those with more of a cosmetic practice. Pay differences compared with those in private practice and missed opportunities for resident teaching were also common themes. Chairs commented that microvascular reconstruction was an important emphasis in their programs.

Our study had several limitations that should be mentioned. As with any survey, variable and low response rates will exist. This was particularly evident with the response rate for the survey of department chairs regarding faculty facial plastic surgeons' group, in which only 20 out of 120 Chairs responded. We noticed that multiple questions were skipped by facial plastic surgeon respondents, which undoubtedly affected our results. Because of this, the generalizability of the results should be exercised with caution. The distinction in academic facial plastic surgeons was not clearly defined, with our results also incorporating those with only loose affiliations. Finally, there is opinion bias, which may construe the results. Further, well-designed studies that develop specific strategies to increase retention of these faculty members should be considered.

\section{Conclusion}

In our study, we identified the need for increased control over the facial plastic surgery practice as a major area for improvement shared between facial plastic surgeon faculty and department Chairs. By focusing on this area, among others, we believe that there will be increased faculty retention, improved patient care, continued resident education, and support garnered from organizations like the AAFPRS and AADO.

Conflicts of Interest

The authors have no conflicts of interest to report.

\section{References}

1 Straus SE, Straus C, Tzanetos K; International Campaign to Revitalise Academic Medicine. Career choice in academic medicine: systematic review. J Gen Intern Med 2006;21(12):1222-1229

2 Pololi LH, Krupat E, Civian JT, Ash AS, Brennan RT. Why are a quarter of faculty considering leaving academic medicine? A study of their perceptions of institutional culture and intentions to leave at 26 representative U.S. medical schools. Acad Med 2012;87(07): 859-869

3 Rao SK, Kimball AB, Lehrhoff SR, et al. The impact of administrative burden on academic physicians: results of a hospital-wide physician survey. Acad Med 2017;92(02):237-243

4 Wai PY, Dandar V, Radosevich DM, Brubaker L, Kuo PC. Engagement, workplace satisfaction, and retention of surgical specialists in academic medicine in the United States. J Am Coll Surg 2014; 219(01):31-42

5 Zetrenne E, Kosins AM, Wirth GA, Bui A, Evans GRD, Wells JH. Academic plastic surgery: a study of current issues and future challenges. Ann Plast Surg 2008;60(06):679-683

6 PwC Health Research Institute. The future of the academic medical center: strategies to avoid a margin meltdown. February 2012. https://www.pwc.com/us/en/health-industries/health-researchinstitute/publications/pdf/the-future-of-academic-medical-centers.pdf

7 Jumaily JS, Spiegel JH. The unique practice needs of academic facial plastic and reconstructive surgeons. JAMA Facial Plast Surg 2015;17(05):384-385

8 Pololi L, Knight S. Mentoring faculty in academic medicine. A new paradigm? J Gen Intern Med 2005;20(09):866-870 